\title{
Baculovirus Mediated Experimental Research on Targeted Egr1-Kringle 5 Gene Radiotherapy in Lung Adenocarcinoma
}

\author{
Haoping Xu, Rui Guo, Biao $\mathrm{Li}^{*}$ \\ Department of Nuclear Medicine, Rui Jin Hospital, Shanghai Jiao Tong University School of Medicine, Shanghai, China. \\ Email: *1b10363@rjh.com.cn
}

Received April 15 $5^{\text {th }}, 2012$; revised May 27 $7^{\text {th }}, 2012$; accepted June $15^{\text {th }}, 2012$

\begin{abstract}
Objective: To investigate the feasibility of temporally and spatially restricted Kringle 5 expression induced by radiation, as well as the dual effect of radiotherapy and antiangiogenic therapy in lung adenocarcinoma in vitro. Methods: We first constructed recombinant baculovirus vectors containing Egrl promoter and human plasminogen Kringle5 gene (rhK5), then transfected them into lung adenocarcinoma cells (A549). Transfect efficiency of the baculovirus for gene transfer in A549 cells and the activity of Egr1 promoter induced by X-radiation were detected by fluorescence microscopy. The rhK5 mRNA transcription and rhK5 protein expression were detected by Real-time PCR and Western blot assay, respectively. The apoptosis asssay of human umbilical veins endothelial cells (HUVEC) was analyzed by flow cytometry. Results: The recombinant baculovirus were successfully transfected into A549 and HUVEC cells. As for the temporal regulation, the rhK5 mRNA transcription and rhK5 protein expression were elevated with the irradiation time significantly. And the HUVEC apoptotic percentage increased in relation to the irradiation time as well. As for the spatial regulation, rhK5 mRNA transcription level of A549 cell lines transfected with recombinant baculovirus Egr1-K5 was significantly higher than that of control groups after the same dose of X-radiation. When we analyzed the dose and frequency of X-radiation, no difference was observed among each dose after continuously three-times of irradiation. Conclusion: Baculovirus-mediated Egr1-K5 can be used in gene radiotherapy for its temporary and spatial controllable rhK5 expression by X-radiation and the consequent HUVEC apoptosis in vitro study. And low dose and more times of irradiation might be more effective. It would provide a promising way for the tumor treatment.
\end{abstract}

Keywords: Radiotherapy; Lung Adenocarcinoma; Egr1 Promoter; Kringle 5; Baculovirus

\section{Introduction}

Radiotherapy is widely used in the treatment of various types of cancer. However, its application is limited by the side-effects such as the radiation-induced damages of the normal tissues nearby and the radiation-resistance of certain tumors. As for the gene therapy, the results are less encouraging due to the inability to optimally localize the activity of therapeutic agents to tumor cells and limit damage to normal tissue. Also, there is a lack of effective therapeutic gene.

Angiogenesis plays a key role in tumor progression. It was hypothesized that inhibition of angiogenesis would be an effective strategy to treat human cancer, and an active search for angiogenesis inducers and inhibitors began in 1971 [1]. Antiangiogenic therapy could destroy tumor vasculature and inhibit tumor growth. And it's therapeutic benefit may even be greater when used in com-

${ }^{*}$ Corresponding author. bination with established treatment modalities, such as surgery, chemotherapy, and radiation therapy [2]. Plasminogen contains 5 kringles, and kringle 1 - 4 consists of angiostatin. The kringle 5 (K5) domain of human plasminogen with low molecular weight of $14 \mathrm{kDa}$ and low immunogenicity is a specific inhibitor for endothelial cell proliferation and displays powerful antiangiogenic activity [3]. Study also showed that kringle 5 could directly lead to apoptosis of anoxic tumor cells in vitro [4]. These features make $\mathrm{K} 5$ an appealing antitumor biopharmaceutical with combined antitumoral and antiangiogenic properties. Although angiogenesis inhibition offers several advantages, it is expected to induce a cytostatic effect resulting in tumor stabilization not eradication. Furthermore, single-agent antiangiogenic therapy may lead to a compensatory increase in the production of other angiogenic factors, which may then sustain angiogenesis [5]. In a recent study, the therapeutic effect of radiotherapy combined with K5 is investigated in Lewis lung carci- 
noma (LLC) tumor model, which indicated that there is significant additive effect when radiotherapy was combined with K5. The mechanism of the effect might be related to the increased sensitivity of both tumor cells and vascular endothelial cells to ionizing radiation induced by K5 [6]. However, without specificity, this combined treatment made no effort to avoid the damage to surrounding normal tissue.

In our research, we designed to construct K5 gene downstream the Egr1 (Early growth response gene-1) promoter in order to target gene expression with radiotherapy spatially and temporally to decrease the damage of normal tissue nearby eventually. Previous studies have shown that the six 5' $\mathrm{CarG}[\mathrm{CC}(\mathrm{A}+\mathrm{T}$ rich $) \mathrm{GG}]$ elements mediate transcriptional induction of the Egrl gene promoter following ionizing radiation $[7,8]$. It is an effective approach that uses the specificity of the Egrl promoter to construct the radiation-inducible gene expression system with destination gene $[9,10]$.

The Recombinant baculoviruses were designed as vectors for specific gene transfer in our research. The vector for gene transfer is a major challenge in medical research. And the research has showed that viral vectors are the most efficient tools for genetic modification of the majority of somatic cells in vitro and in vivo [11]. Recombinant baculoviruses with a mammalian expression promoter have recently been viewed as a new generation of gene therapy vehicles holding a great promise $[12,13]$. The baculovirus genome is large and thus large transgenes can be accommodated. In addition, they are easy to scale up and obtain high levels of recombinant gene expression [14].

In the present study, we developed a recombinant baculovirus vector encoding Egr1 promoter and its downstream gene $\mathrm{K} 5$ to investigate the feasibility of temporally and spatially restricted $\mathrm{K} 5$ expression induced by radiation, as well as the dual effect of radiotherapy and antiangiogenic therapy in lung adenocarcinoma models (Figure 1). The main idea of our research is as follows. After Egr1 promoter activated by the radiation, its downstream gene, K5 will start its transcription and protein expression. Thus, suppression of tumor vessels by K5 and the direct killing of tumor cells by radiation will work simultaneously, providing a promising way for tumor treatment.

\section{Materials and Methods}

\subsection{Plasmid Construction}

The plasmid pGL3-Egr1 promoter was kindly provided by Professor Gerald Thiel (Department of Medical Biochemistry and Molecular Biology, Germany). The plasmid pET22b-K5 (His-tagged) was constructed previously

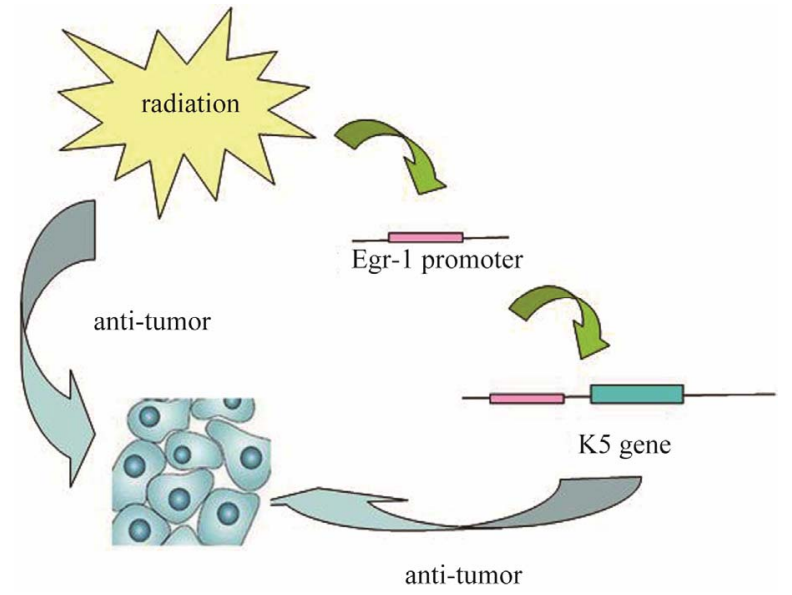

Figure 1. The main idea of our research (After Egr-1 promoter activated by the radiation, its downstream gene, Kringle5 (K5), will start its transcription and protein expression. Suppression of tumor vessels by $\mathrm{K} 5$ and the direct killing of tumor cells by radiation will work simultaneously).

in our laboratory. A 255-bp fragment of human K5 was obtained by double restriction digestion of plasmid pET22b-K5 with BgI II/HindIII and was cloned into the plasmid pGL3 downstream the Egr1 promoter with two cohesive ends.

\subsection{Recombinant Plasmid Construction and Baculovirus Generation}

The template is used to format your paper and style the text. All margins, column widths, line spaces, and text fonts are prescribed; please do not alter them. You may note peculiarities. For example, the head margin in this template measures proportionately more than is customary. This measurement and others are deliberate, using specifications that anticipate your paper as one part of the entire proceedings, and not as an independent document. Please do not revise any of the current designations. The baculovirus plasmid pFB-NES1 was constructed previously in our laboratory [15]. The Egr1-K5 fragment was amplified by polymerase chain reaction using the reconstructed plasmid pGL3 above as a template with the forward primer 5'-AGTGCAAGTGCAGGTGCCAGAACATTTC-3' and the reverse primer 5'-TTCCATGGTGGCTTTACCAACAGTACCG-3'. Amplification was performed for 35 cycles at $95^{\circ} \mathrm{C}$ for $30 \mathrm{~s}, 60^{\circ} \mathrm{C}$ for $1.5 \mathrm{~min}$, and $72^{\circ} \mathrm{C}$ for $1 \mathrm{~min}$. Then the products were digested by restriction endonuclease Mlu/SalI and were ligated to the vector $p F B-N E S 1$, replacing the NES1 fragment to create the recombinant baculovirus plasmid pFB-Egr1-K5. Recombinant baculoviruses were generated and propagated in spodotera frugiperda (Sf-9) insect cells by a Bac-toBac system according to standard manual (Invitrogen). 
Once the viruses were amplified, EGFP expression was observed under a fluorescent microscope to assess the activity of Egr1 promoter stimulated by $5 \mathrm{~Gy}$ X-radiation and the transfect efficiency of baculovirus gene into A549 cells or HUVEC cell. The viruses were amplified to a high titer by propagation in Sf-9 cells and stored in small aliquots at $-80^{\circ} \mathrm{C}$. Viral titers were determined by plaque assay on Sf-9 insect cells. As we reported previously [16], a multiplicity of infection (MOI) of 50 was selected for the following baculovirus experiments.

\subsection{In Vitro Experiments, the Capacity of Temporal Regulation}

\subsubsection{Cell Line Culture, Recombinant Baculovirus Infection and Cell Irradiation}

Human lung adenocarcinoma cells (A549), HUVEC cells (human umbilical veins endothelial cells) and Sf-9 cells were preserved in our laboratory. A549 cells and HUVEC cells were maintained in Dulbecco's modified Eagle's medium (DMEM, Gibco), supplemented with 10\% FBS (fetal bovine serum, Gibco), under standard cell culture conditions $\left(5 \% \mathrm{CO} 2,37^{\circ} \mathrm{C}\right)$. Sf-9 cells were cultured at $27^{\circ} \mathrm{C}$ in a spinner culture bottle containing Sf900II(Gibco) supplemented with 4\% FBS.

To infected with the recombinant baculovirus, A549 cells and HUVEC cells were plated at a density of $10^{6}$ cells per well in 6-well plates in serum-free DMEM. After $24 \mathrm{~h}$, the culture was infected with the recombinant baculovirus at $37^{\circ} \mathrm{C}$ for $1 \mathrm{~h}$, with sodium butyrate supplemented to a final concentration of $10 \mathrm{mmol} / \mathrm{L}$ to enhance the infection efficiency. The medium was replaced with fresh DMEM containing 10\% FBS. After another 24 $\mathrm{h}$ of incubation, the cells were irradiated with X-radiation (6 MV, ELEKTA Precise linear accelerator) of different doses (0 Gy, 1 Gy, 2 Gy, 4 Gy, 6 Gy, 8 Gy and 10 Gy). Cells were harvested $24 \mathrm{~h}$ after irradiation and ready for the following experiments.

\subsection{2. rhK5 mRNA Transcription under Different Irradiation Doses}

Total RNA of human A549 cells was extracted using RNeasy Mini Kit (Qiagen) following the protocol provided by the manufacturer. RNA integrity was checked by electrophoresis and quantified by absorption at 260 $\mathrm{nm}$ and $280 \mathrm{~nm}$ using a UV-visible spectrophotometer (Beckman Coulter Du 800). Reverse transcription reactions were performed on $800 \mathrm{ng}$ total RNA by two steps of elimination of genomic DNA and reverse transcription according to the instructions using the Quanti Tect Rev. Transcription Kit (Qiagen). Quantitative real-time PCR assay was performed in 96-well plates on a real-time PCR instrument (ABI 7300). The composition of each reaction was as follows in $25 \mu$ final volume $\left(\mathrm{SYBR}^{\circledR}\right.$
PrimeScript ${ }^{\circledR}$ RT-PCR Kit, Takara): $12.5 \mu 1$ of SYBR Premix Ex Taq $(2 \times), 0.5 \mu$ of each primers $(10 \mu \mathrm{M}$ each $)$, $5 \mu \mathrm{l}$ of cDNA and $6.5 \mu \mathrm{l}$ of $\mathrm{ddH}_{2} \mathrm{O}$. The forward primer was 5'-GAAGAAGACTGTATGTTTGGGAATGG-3', and the reverse primer was 5'-GTGGTGGTGGTGGTGGTGGGCCGCACACT-3'. And the program was $95^{\circ} \mathrm{C}$ for $5 \mathrm{~min}$, followed by 40 cycles of $95^{\circ} \mathrm{C}(15 \mathrm{~s}), 60^{\circ} \mathrm{C}(15$ $\mathrm{s})$, and $72^{\circ} \mathrm{C}(30 \mathrm{~s})$.

\subsection{3. rhK5 Protein Expression under Different Irradiation Doses}

Cell lysates were made with standard methods. The protein concentration of each sample was measured using a BCA kit (Pierce). For SDS-PAGE, $30 \mu \mathrm{g}$ of protein samples was loaded on $15 \%$ polyacrylamide gels. Proteins were transferred to a polyvinylidene difluoride membrane with a tank transfer system (Bio-Rad Laboratory), then blocked with a buffer containing 5\% low fat skim milk and $0.1 \%$ Tween-20 in Tris-buffered saline(TBST) at room temperature for $1 \mathrm{~h}$. Primary antibodies were diluted in TBST containing 5\% skim milk. The membrane was incubated with primary antibodies overnight at $4^{\circ} \mathrm{C}$. After washed three times with TBST, the membrane was incubated with a horseradish peroxidase-conjugated secondary antibody $(0.02 \mu \mathrm{g} / \mathrm{mL}$ in TBST) for $1 \mathrm{~h}$ at room temperature. Chemiluminescence was detected with an ECL Western blot detection kit (Amersham, Little Chalfont, UK) according to its manufacturer's instructions. And quantitation was performed using the Gel-Pro system.

\subsubsection{HUVEC Cell Apoptosis Test}

HUVEC cells were divided into two groups according to whether they were infected with recombinant baculovirus. The HUVEC cells were grown to $\sim 80 \%$ confluence in $100 \mathrm{~mm}^{2}$ dishes. The way of recombinant baculovirus infection and irradiation by different doses was described above. Afterthat, cells were trypsinized, centrifuged, aliquoted into tubes and labeled with Annexin V and propidum iodide using FITC Annexin V Apoptosis Detection Kit (BD Pharmingen ${ }^{\mathrm{TM}}$ company). Annexin V and PI staining were performed following the manufacturer's recommendations. Flow cytometry analysis was performed using a FACSCalibur Flow Cytometer (Becton Dickinson) following the manufacturer's recommendations.

\subsection{In Vitro Experiments, the Capacity of Spatial Regulation}

The A549 cells were seeded in 6-well plates before the experiment to achieve a density of $1 \times 10^{6}$ cells/well. We chose four out of six wells in each plate to be X-irradiated and numbered 1, 2, 3, 4. The cells in No. 1, 2, 3 
wells were treated with Bac E (the recombinant baculovirus containing Egrl promoter only), Bac K (the recombinant baculovirus containing $\mathrm{K} 5$ only) and Bac EK (Bac Egr1-K5), respectively. The cells in the No. 4 well were blank controls. The way of cell culture and recombinant baculovirus infection was the same as described above. Twenty-four hours after infection, cells in these four wells were exposed to a single dose of $4 \mathrm{~Gy}$ of $\mathrm{X}$-radiation generated by a linear accelerator. Each plate was irradiated only once. We tested three times with three 6-wells plates in all. Then K5 mRNA transcription of A549 cells in totally 12 wells (3 plates) was analyzed to show the capacity of spatial regulation by Egr1 promoter in our experimental system.

\subsection{Analyze the Dose and the Frequency of X-Radiation Preliminarily}

The A549 cells were grown in 6-well plates, and the way of cell culture and recombinant baculovirus infection was the same as described above. Twenty-four hours after infection, the cells were irradiated with X-radiation of 0 Gy, 1 Gy, 2 Gy, 4 Gy, 6 Gy, 8 Gy and 10 Gy respectively three-times continuously (once a day, three days in all). Cells were harvested $24 \mathrm{~h}$ after irradiation and assayed for K5 mRNA.

\subsection{Statistical Analysis}

Data were analyzed using the SPSS 11.0 software. Each experiment was done in triplicate. The data were presented as mean $\pm \mathrm{SD}$. Comparison among experimental groups was performed using ANVOA test. $P<0.05$ was considered statistically significant. Spearman's correlation tests were conducted to compare $\mathrm{K} 5$ expression and apoptosis percentage of HUVEC cells.

\section{Results}

\subsection{Preparation of the Baculovirus}

We successfully constructed the plasmid pGL3-Egr1-K5 and the recombinant plasmid. Whereafter, we developed a baculovirus-derived vector, containing the K5 gene under control of the Egr1 promoter and named it Bac EK (Bac Egr1-K5). The control vector, Bac E (the recombinant baculovirus containing Egrl promoter only), Bac K (the recombinant baculovirus containing $\mathrm{K} 5$ only) and Bac Egr1-EGFP were also developed. Propagation of these viruses in Sf-9 cells yielded viral stocks with a titer of $1 \times 10^{9} \mathrm{PFU} / \mathrm{mL}$.

\subsection{Transfect Efficiency of Recombinant Baculovirus in A549 Cells and HUVEC Cells}

The transfect efficiency of baculovirus in A549 cells and
HUVEC cells were assessed by fluorescence microscopy after these cells were infected with Bac Egr1-EGFP and get irradiated by $5 \mathrm{~Gy}$ of X-radiation once thereafter. The control groups were infected with recombinant baculovirus only, but not get irradiated. A549 and HUVEC cells infected with Bac Egrl-EGFP 12, 18, 24 and $36 \mathrm{~h}$ after transfection respectively were examined by fluorescence microscopy (Figures 2 and 3), showing that both A549 human lung adenocarcinoma cells and HUVEC cells could be infected with recombinant baculovirus. From these figures, we found that the strongest EGFP expression was detected after $24 \mathrm{~h}$. It also identified the activity of Egr-1 promoter irradiated by X-radiation.

\subsection{In Vitro Experiments, the Capacity of Temporal Regulation}

\subsubsection{Analysis of rhK5 mRNA Transcription after $\mathrm{X}$-Irradiation}

Figure 4 showed the results of real-time PCR in Bac EK group and two control groups $24 \mathrm{~h}$ after the infected A549 cells were treated with single X-irradiation. The transcription level of rhK5 mRNA was elevated with the dose of X-radiation ( $0 \mathrm{~Gy}-10 \mathrm{~Gy}$ ) significantly in Bac

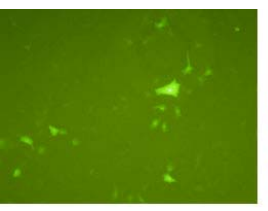

(a)

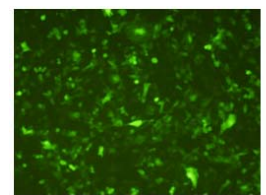

(d)

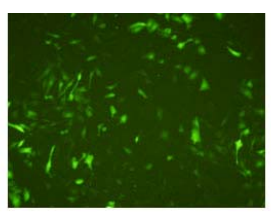

(b)

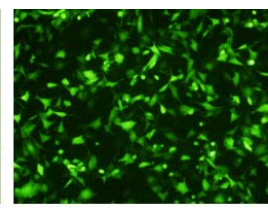

(c)

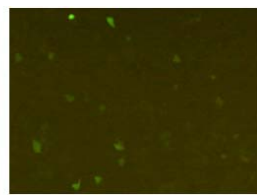

(e)

Figure 2. EGFP expression in A549 cells detected by fluorescence microscopy. (a) $12 \mathrm{~h}$ after the cells get irradiated by 5 Gy X-radiation; (b) $18 \mathrm{~h}$ after the cells get irradiated by 5 Gy X-radiation; (c) $24 \mathrm{~h}$ after the cells get irradiated by 5 Gy X-radiation; (d) $30 \mathrm{~h}$ after the cells get irradiated by 5 Gy X-radiation; (e) without get irradiated by X-radiation (the control).

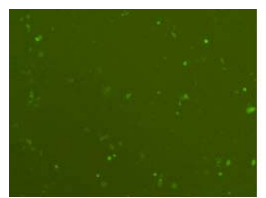

(a)

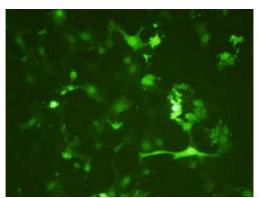

(b)

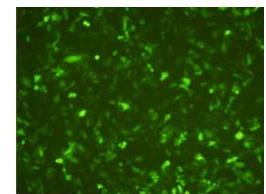

(c)
Figure 3. EGFP expression in HUVEC cells detected by fluorescence microscopy. (a) Without get irradiated by $\mathrm{X}$ radiation ( the control); (b) $18 \mathrm{~h}$ after the cells get irradiated by 5 Gy X-radiation; (c) $24 \mathrm{~h}$ after the cells get irradiated by 5 Gy X-radiation. 


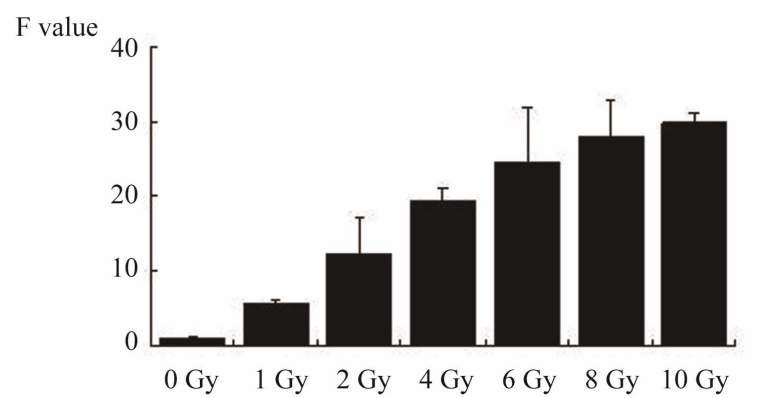

F value

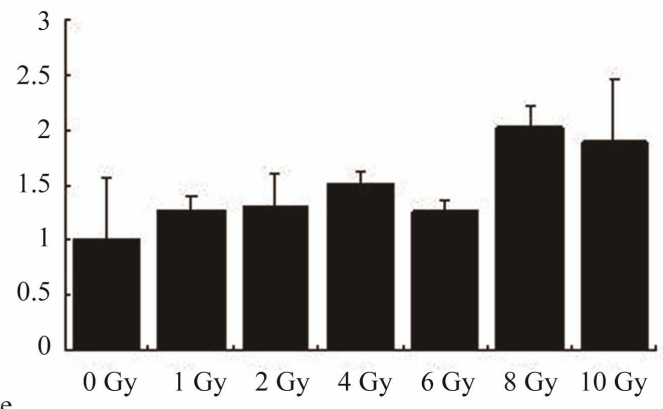

F value

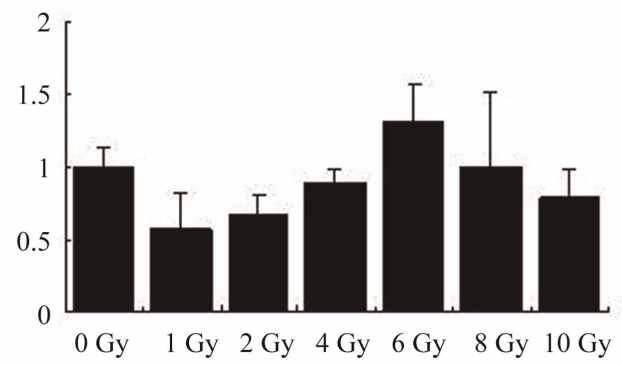

Figure 4. Kringle5 mRNA transcription in the infected A549 cells analyzed by real-time PCR (with single X-irradiation). From top to bottom: in Bac EK group, in Bac $K$ group and in Bac E group.

EK group $(P<0.05)$, but not in the two control groups $(P$ $>0.05)$.

\subsection{2. rhK5 Expression in the Infected A549 Cells after X-Irradiation}

Western Blot analysis was performed using antibodies to 6-histidine (His-tagged K5) for the expression of rhK5 in A549 cells infected with recombinant baculoviruses (Bac EK). A polyclonal antibody to 6-histidine detected a single protein band at $14 \mathrm{kDa}$ in the Bac EK group (Figure 5). Quantitative evaluation showed (Figure 6) that the rhK5 expression increased with the dose of radiation significantly $(P<0.05)$.

\subsubsection{Cell Apoptosis Assay Results of Infected HUVEC Cells after X-Radiation}

The dual parameter fluorescent dot plots (Figure 7) shows the viable cell population in the lower left quadrant (negative annexin-FITC and negative PI), the cells at
Bac EK

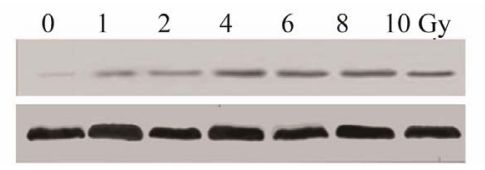

(a)

Bac K

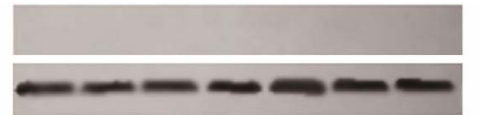

(b)

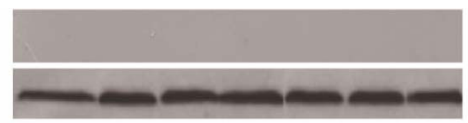

(c)
K5

GAPDH

K5 GAPDH

K5

GAPDH

Figure 5. Kringle 5 expression in the infected A549 cells detected by Western blot $24 \mathrm{~h}$ after X-radiation. (a) In EK group, a single protein band at $14 \mathrm{kDa}$ (Kringle5); (b) In Bac K group, no kringle5 expression; (c) In Bac E group, no Kringle5 expression.

$$
\mathrm{IOD}_{\mathrm{K} 5} / \mathrm{IOD}_{\mathrm{GAPDH}}
$$

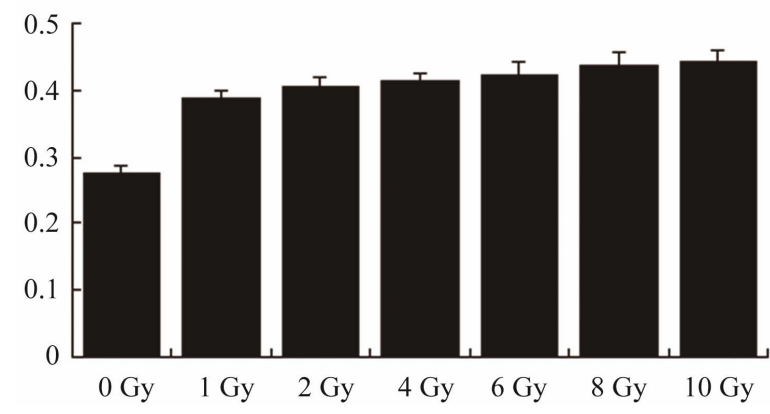

Figure 6. The quantitative evaluation of K5 expression: Integrated optical density (IOD) was measured and analyzed by software Gel-pro 4.0. The value of $\mathrm{IOD}_{\mathrm{K} 5} / \mathrm{IOD}_{\mathrm{GAPDH}}$ was showed in 0 Gy, 1 Gy, 2 Gy, 4 Gy, 6 Gy, 8 Gy and 10 Gy. Dose dependent $\mathrm{K} 5$ expression was observed.

the early apoptosis are in the lower right quadrant (positive annexin-FITC and negative PI) while the ones at the late apoptosis are in the upper right quadrant (positive annexin-FITC and positive-PI).

As seen in Table 1, the early apoptotic cells percentage increased in relation to the dose of $\mathrm{X}$-radiation $(P<$ $0.05)$ both in Bac EK plus radiotherapy group and the control radiotherapy alone group. Moreover, of the same dose of X-radiation, the apoptotic cells percentage of Bac EK plus radiotherapy group was significantly higher than that of radiotherapy alone group $(P<0.05)$. However, in Bac E and Bac K groups, no significant differences of the early apoptotic cells percentage was detected between Bac E/Bac K plus radiotherapy group and radiotherapy alone group $(P>0.05)$. These data suggest that Bac EK plus radiotherapy do best increase apoptosis of HUVEC cells compared with radiotherapy alone as the Egr-1 promoter was activated by radiotherapy and K5 played a 


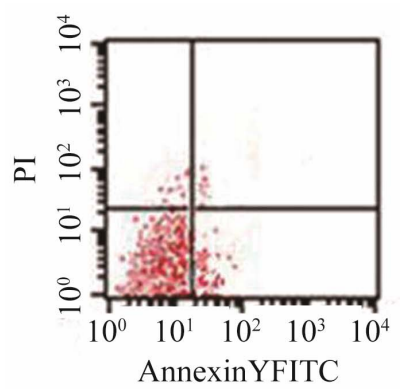

(1)

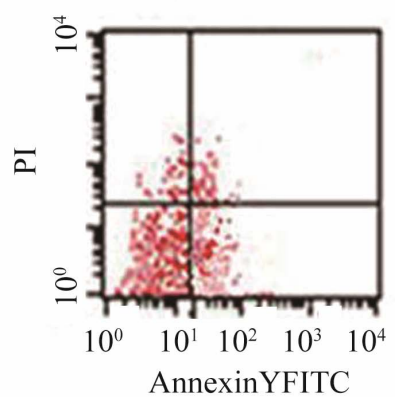

(5)

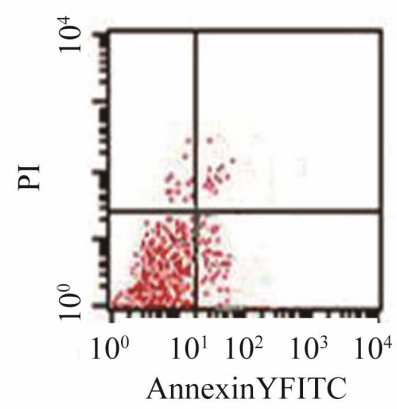

(8)

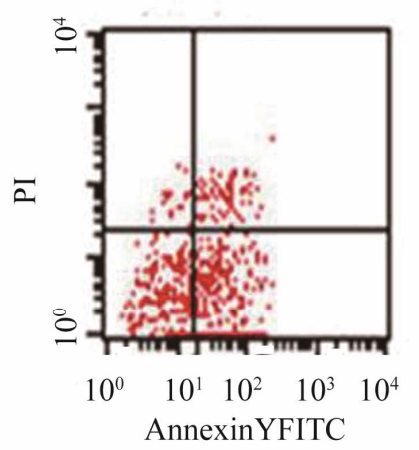

(12)

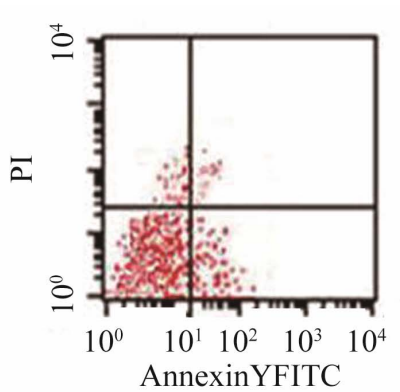

(2)

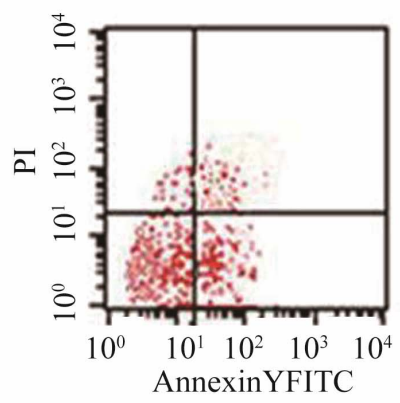

(6)

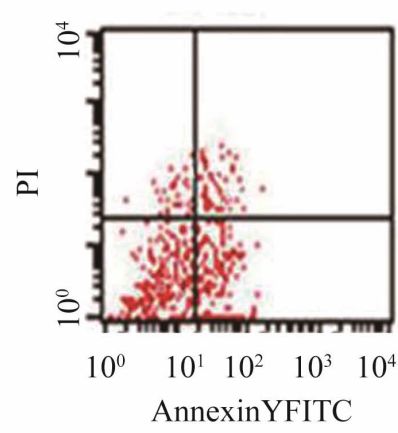

(9)

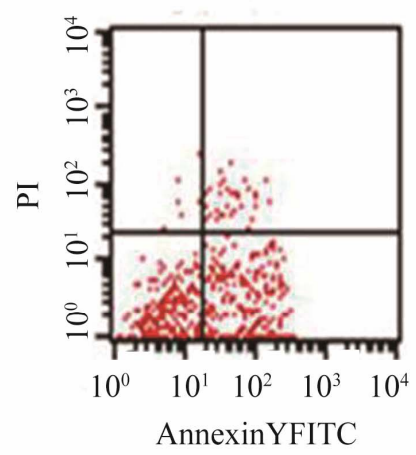

(13)

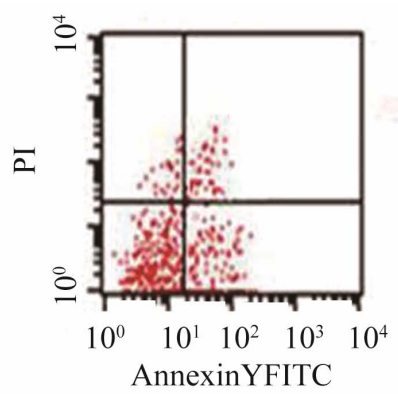

(3)

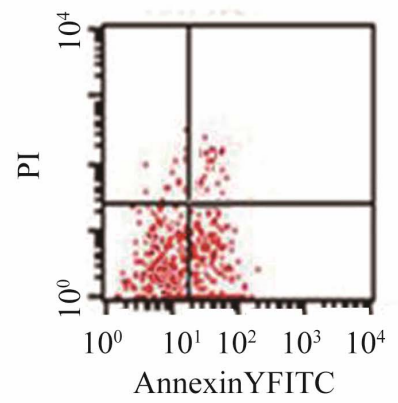

(7)

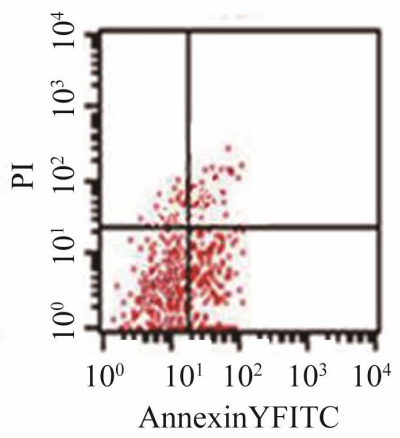

(10)

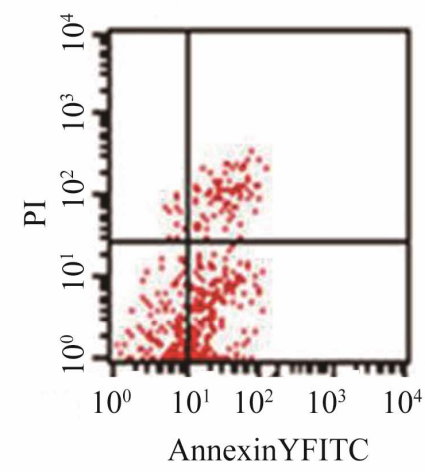

(14)

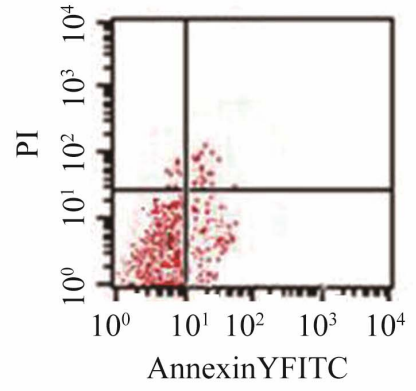

(4)

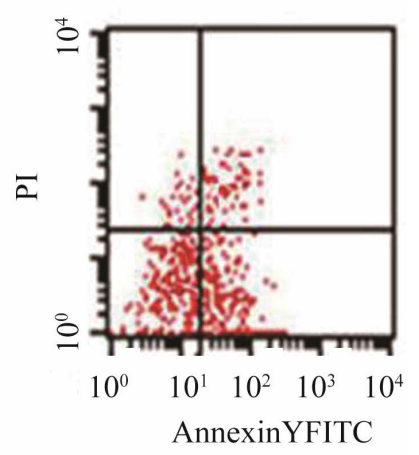

(11)

Figure 7. Apoptotic effect of HUVEC cells $24 \mathrm{~h}$ after radiotherapy with or without Bac EK infection were determined by flow cytometry analysis using annexin V-FITC and propidium iodide. Cell population in bottom left, bottom right, top right and top left quadrants represented the proportion of viable cells, early apoptotic cells, late apoptotic cells and necrotic cells, respectively. Radiotherapy alone: (1) 0 Gy; (2) 1 Gy; (3) 2 Gy; (4) 4 Gy; (5) 6 Gy; (6) 8 Gy; (7) 10 Gy; Radiotherapy with Bac EK: (8) 0 Gy; (9) 1 Gy; (10) 2 Gy; (11) 4 Gy; (12) 6 Gy; (13) 8 Gy; (14)10 Gy. 
Table 1 . The early apoptotic cells percentage detected by fluorescence microscopy.

\begin{tabular}{lcc}
\hline & Bac Egr-1-K5 with R (\%) & R alone (\%) \\
\hline 0 Gy & $10.67 \pm 1.36$ & $8.01 \pm 1.85$ \\
1 Gy & $32.16 \pm 3.73$ & $13.38 \pm 2.51$ \\
2 Gy & $34.66 \pm 3.22$ & $14.4 \pm 4.17$ \\
4 Gy & $41.52 \pm 5.26$ & $21.43 \pm 1.39$ \\
6 Gy & $44.42 \pm 4.38$ & $23.92 \pm 5.76$ \\
8 Gy & $49.06 \pm 5.91$ & $29.93 \pm 3.17$ \\
$10 \mathrm{~Gy}$ & $52.55 \pm 3.24$ & $36.49 \pm 4.62$ \\
\hline
\end{tabular}

$\mathrm{R}$ : radiotherapy.

part in accelerating the cell apoptosis.

\subsection{In Vitro Experiments, the Capacity of Spatial Regulation}

The real-time PCR results showed that the transcription of rhK5 mRNA in No.4 wells was significantly higher than those in other three wells $(P<0.05)$. The spatial regulation could be realized through the control of rhK5 expression.

\subsection{Analyze the Dose and the Frequency of X-Radiation Preliminarily}

When we analyzed the K5 mRNA transcription in Bac EK group after the infected A549 cells were treated with continuously three-times of X-radiation (the same fractionated dose as single irradiation, once a day, 3 days in all), no significant difference was seen among these groups of different fractionated doses (Figure 8).

\section{Discussion}

Most nonsmall cell lung cancer (NSCLC) patients were diagnosed at advanced stage and radiotherapy remains the treatment choice in such patients. Chemotherapy in combination with radiotherapy significantly improves the survival rate. However, the complete response rates are low and long-term survival remains poor, and the cytotoxicity of chemotherapy is severe. All these indicate that exploration of more potent and safe therapeutic modalities is needed. The combination of gene therapy and radiotherapy has the potential to overcome many of the limitations of adverse tumor biology on cancer treatment and appears to be a promising approach to increase the therapeutic ratio of cancer therapy. In this study, the vector containing Egr1 promoter and its downstream K5 gene, an antiangiogenic agent gene, was constructed and tested by fluorescence microscopy for the ability of Egr1 promoter to regulate heterologous gene expression. The results of what the fluorescence microscopy showed also

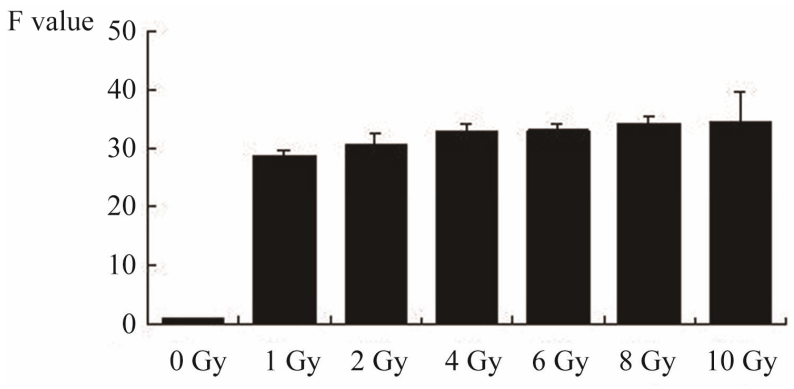

Figure 8. Kringle 5 mRNA transcription in the infected A549 cells analyzed by real-time PCR (with continuously three-times of $\mathrm{X}$-radiation) of Bac EK group.

identified that radiation can induce the transcription of Egr1 as reported previously $[9,17]$, and laid the groundwork for the next research.

There are several potential advantages in using radiation-inducible genetic constructs with therapeutic radiation over other gene therapy delivery systems for cancer treatment. One advantage is that the already well-developed technology of radiation targeting might add to the localization of toxin production provided by genetic therapy. As our study showed, when infected HUVEC cells received the same dose of X-radiation, the apoptotic cells percentage of "Bac EK plus radiotherapy" group was significantly higher than that of radiotherapy alone group $(P<0.05)$. A number of preclinical studies have indicated that antiangiogenic agents can enhance the tumor response to radiation $[18,19]$. Under X-radiationinduced cell stress condition, $\mathrm{K} 5$ could produce additive effect on endothelial cell apoptosis. Another advantage is that it controls gene expression spatially and temporally. The system we describe exploits the benefits of a tumorspecific vector in combination with radiotherapy which triggers and increases gene expression. Since therapeutic agents such as K5 might bring sideeffects to normal tissues, spatial control of protein expression can be very beneficial to limit $\mathrm{K} 5$ expressing locally in the tumor.

There are two challenges in this method when it is projected as a gene therapy strategy against cancer cells. First, introduction of the Egr1 promoter-driven antiangiogenic gene to the tumor site would require an appropriate vector. The therapeutic gene must be present in the cancer cells when the tumor is irradiated by the X-radiation. However, specific irradiation of the tumor site with radiotherapy may give us specific activation of Egrl promoter in the tumor cells. Autograps californica multiple nucleopolyhedrovirus (AcMNPV)-based vector, traditionally used as a biopesticide to kill infected inserts, is recently tested as a new type of delivery vehicle for transgene expression in mammalian cells [20]. These viruses can enter but not replicate in mammalian cells. With mammalian expression promoters, recombinant 
baculoviruses provide a high transduction efficiency in different cells and tissues, including several tumor cell lines [21]. One of the attractive advantages of using AcMNPV as a cancer gene therapy vector is the large cloning capacity conferred by its 130 -kb viral genome, which may be used to deliver a large functional gene or multiple genes from a single vector [22]. Other empirical advantages of baculovirus vectors include easy construction of a recombinant viral vector and simple procedure of purifying large quantities of viruses with high titers. It would be possible to scale up the less labor-intensive process to pharmaceutical levels [23]. A second problem is the dose and the frequency of X-radiation to activate Egr1 promoter and work as radiotherapy at the same time. We found that the K5 expression activated by Egr1 promoter dose-dependently increased in this vitro study, that is, the most $\mathrm{K} 5$ expression was achieved using $10 \mathrm{~Gy}$, the highest dose in our study. Since a dose of $10 \mathrm{~Gy}$ is not used in a curative treatment setting, and patients are not treated with a single dose of irradiation but with fractionated radiotherapy, we tried using continuously threetimes of X-radiation. To our surprise, the study demonstrated that there's no significant difference of K5 expression between high-dose groups and low-dose groups after three times of irradiation. On the basis of these results we deduce this daily repeated small irradiation dose results in the same activation efficiency of Egr1 promoter. The mechanism has not been available yet. Moreover, irradiated by 2 Gy daily is suitable for clinical treatment and may decrease normal tissue toxicity compared with a single large dose.

In summary, we report one therapeutic system with radiation-inducible promoter, Egrl, which made it have the capacity of temporal regulation as well as spatial regulation. In this system, radiotherapy and gene therapy worked simultaneously, and their effects were greater than those of either modality alone. Low dose and more times might be the most efficient therapeutic model of this combined system. On the basis of the results above, further study in vivo has been carried on to observe the effect of this therapeutic system. And the potential benefits of exogenous gene induction by radiotherapy include increased local tumor control as well as the potential for treatment of metastatic disease.

\section{Acknowledgements}

This work was supported by Shanghai Leading Academic Discipline Project S30203.

\section{REFERENCES}

[1] J. Folkman, E. Merler, C. Abernathy and G. Williams, "Isolation of a Tumor Factor Responsible for Angiogene- sis," Journal of Experimental Medicine, Vol. 133, No. 2, 1971, pp. 275-288. doi:10.1084/jem.133.2.275

[2] P. Wachsberger, R. Burd and A. P. Dicker, "Tumor Response to Ionizing Radiation Combined with Antiangiogenesis or Vascular Targeting Agents: Exploring Mechanisms of Interaction," Clinical Cancer Research, Vol. 9, No. 6, 2003, pp. 1957-1971.

[3] Y. Cao, R. Cao and N. Veitonmaki, "Kringle Structures and Antiangiogenesis," Current Medicinal ChemistryAnti-Cancer Agents, Vol. 2, No. 6, 2002, pp. 667-681. doi:10.2174/1568011023353705

[4] D. J. Davidson, C. Haskell, S. Majest, A. Kherzai, D. A. Egan, K. A. Walter, et al., "Kringle 5 of Human Plasminogen Induces Apoptosis of Endothelial and Tumor Cells through Surface-Expressed Glucose-Regulated Protein 78," Cancer Research, Vol. 65, No. 11, 2005, pp. $4663-$ 4672. doi:10.1158/0008-5472.CAN-04-3426

[5] L. Bello, C. Giussani, G. Carrabba, M. Pluderi, F. Costa and A. Bikfalvi, "Angiogenesis and Invasion in Gliomas," Cancer Treatment and Research, Vol. 117, 2004, pp. 263-284. doi:10.1007/978-1-4419-8871-3 16

[6] G.-H. Jin, D.-Y. Ma, N. Wu, F. M. M. T. Marikar, S.-Z. Jin, W.-W. Jiang, et al., "Combination of Human Plasminogen Kringle 5 with Ionizing Radiation Significantly Enhances the Efficacy of Antitumor Effect," International Journal of Cancer, Vol. 121, No. 11, 2007, pp. 2539-2546. doi:10.1002/ijc.22708

[7] M. M. Ahmed, "Regulation of Radiation-Induced Apoptosis by Early Growth Response-1 Gene in Solid Tumors," Current Cancer Drug Targets, Vol. 4, No. 1, 2004, pp. 43-52. doi:10.2174/1568009043481704

[8] O. Greco, B. Marples, G. U. Dachs, K. J. Williams, A. V. Patterson and S. D. Scott, "Novel Chimeric Gene Promoters Responsive to Hypoxia and Ionizing Radiation," Gene Therapy, Vol. 9, No. 20, 2002, pp. 1403-1411. doi:10.1038/sj.gt.3301823

[9] M. Y. Wu, X. Y. Wu, Q. S. Li and R. M. Zheng, "Expression of Egr-1 Gene and Its Correlation with the Oncogene Proteins in Non-Irradiated and Irradiated Esophageal Squamous Cell Carcinoma," Diseases of the Esophagus, Vol. 19, No. 4, 2006, pp. 267-272. doi:10.1111/j.1442-2050.2006.00575.x

[10] H. B. Ma, X. J. Wang, Z. L. Di, H. Xia, Z. Li, J. Liu, et al., "Construction of Targeted Plasmid Vector pcDNA3.1Egr.1p-p16 and Its Expression in Pancreatic Cancer JF305 Cells Induced by Radiation in Vitro," World Journal of Gastroenterology, Vol. 13, No. 31, 2007, pp. 42144218.

[11] N. Khalighinejad, H. Hariri, O. Behnamfar, A. Yousefi and A. Momeni, "Adenoviral Gene Therapy in Gastric Cancer: A Review," World Journal of Gastroenterology, Vol. 14, No. 2, 2008, pp. 180-184. doi:10.3748/wjg. 14.180

[12] F. M. Boyce and N. L. Bucher, "Baculovirus-Mediated Gene Transfer into Mammalian Cells," Proceedings of the National Academy of Sciences USA, Vol. 93, No. 6, 1996, pp. 2348-2352. doi:10.1073/pnas.93.6.2348

[13] H. Matilainen, J. Rinne, L. Gilbert, V. Marjomaki, H. 
Reunanen and C. Oker-Blom, "Baculovirus Entry into Human Hepatoma Cells," Journal of Virology, Vol. 79, No. 24, 2005, pp. 15452-15459. doi:10.1128/JVI.79.24.15452-15459.2005

[14] D. L. Jarvis and A. Garcia Jr., "Long-Term Stability of Baculoviruses Stored under Various Conditions," Biotechniques, Vol. 16, 1994, pp. 508-513.

[15] W. Huang, X. L. Tian, Y. L. Wu, J. Zhong, L. F. Yu, S. P. $\mathrm{Hu}$, et al., "Suppression of Gastric Cancer Growth by Baculovirus Vectormediated Transfer of Normal Epithelial Cell Specific-1 Gene," World Journal of Gastroenterology, Vol. 14, No. 38, 2008, pp. 5810-5815. doi:10.3748/wjg. 14.5810

[16] R. Guo, Y. F. Zhang, S. Liang, H. P. Xu, M. Zhang and B. Li, "Sodium Butyrate Enhances the Expression of Baculovirus-Mediated Sodium/Iodide Symporter Gene in A549 Lung Adenocarcinoma Cells," Nuclear Medicine Communications, Vol. 31, No. 10, 2010, pp. 916-921.

[17] J. M. McLoughlin, T. M. McCarty, C. Cunningham, V. Clark, N. Senzer, J. Nemunaitis, et al., "TNFerade, an Adenovector Carrying the Transgene forHuman Tumor Necrosis Factor a, for Patients with Advanced Solid Tumors: Surgical Experience and Long-Term Follow-Up," Annals of Surgical Oncology, Vol.12, No.10, 2005, pp. 825-830. doi:10.1245/ASO.2005.03.023

[18] R. P. Dings, B. W. Williams, C. W. Song, A. W. Griffioen, K. H. Mayo and R. J. Griffin, "Anginex Synergizes with Radiation Therapy to Inhibit Tumor Growth by Ra- diosensitizing Endothelial Cells," International Journal of Cancer, Vol. 115, No. 2, 2005, pp. 312-319. doi:10.1002/ijc. 20850

[19] S. Nasu, K. K. Ang, Z. Fan and L. Milas, "C225 Antiepidermal Growth Factor Receptor Antibody Enhances Tumor Radiocurability," International Journal of Radiation Oncology•Biology•Physics, Vol. 51, No. 2, 2001, pp. 474 477.

[20] J. P. Condreay and T. A. Kost, "Baculovirus Expression Vectors for Insect and Mammalian Cells," Current Drug Targets, Vol. 8, No. 10, 2007, pp. 1126-1131. doi:10.2174/138945007782151351

[21] C. Hofmann, V. Sandig, G. Jennings, M. Rudolph, P. Schlag and M. Strauss, "Efficient Gene Transfer into Human Hepatocytes by Baculovirus Vectors," Proceedings of the National Academy of Sciences of the USA, Vol. 92, 1995, pp. 10099-10103. doi:10.1073/pnas.92.22.10099

[22] T. A. Kost and J. P. Condreay, "Recombinant Baculoviruses as Mammalian Cell Gene-Delivery Vectors," Trends in Biotechnology, Vol. 20, No. 4, 2002, pp. 173- 180. doi:10.1016/S0167-7799(01)01911-4

[23] S. Ghosh, M. K. Parvez, K. Banerjee, S. K. Sarin and S. E. Hasnain, "Baculovirus as Mammalian Cell Expression Vector for Gene Therapy: An Emerging Strategy," Molecular Therapy, Vol. 6, No. 1, 2002, pp. 5-11. doi:10.1006/mthe.2000.0643 